
PURVIS: THE ABSORPTION SPECTRA OF VARIOUS

\title{
LVIII.-The Absorption Spectra of Various Halogen and Nitrile Derivatives of Benzene and Toluene as Vapours and in Solution.
}

\section{By John Edward Purvis.}

THE author has described and discussed in earlier communications the absorption spectra of the vapours and solutions of various halogen derivatives of benzene and toluene (T., 1911, 99, 811, 1699, 2318). It was proved, amongst other phenomena, that the iodine derivatives had no selective absorption in the ultra-violet regions, whereas the corresponding chlorine and bromine compounds had a large number of vapour bands and a smaller number of solution bands.

Later investigations (Purvis and McCleland, T., 1913, 103, 1088 ; Purvis, ibid., p. 1638) showed that the iodoanilines, p-iodophenol, the nitrobenzenes, the nitrotoluenes, o-nitrophenol, o-nitroanisole, $o$-nitroaniline, and the nitrobenzaldehydes had none of the numerous vapour bands found in benzene, toluene, aniline, phenol, and benzaldehyde. It was also shown that the finer vapour bands were eliminated as the number of chlorine or bromine atoms in the nucleus increased; for example, in 2:4-dichloroaniline, and in 2:4:6-trichloro- and tribromo-phenols, the phenomena became comparable with the solution phenomena.

This communication describes the results obtained when other halogen and various nitrile derivatives of benzene and toluene were investigated, in order to see how far the absorption is affected (1) by the introduction in the benzene nucleus of the two dissimilar atoms of chlorine and bromine, as in the $o_{-}, m-$ and $p$-chlorobromobenzenes, as compared with the dichloro- and dibromo-benzenes and with benzyl chloride, (2) by the introduction of the nitrile group, as in benzonitrile and the $o-, m$, and $p$-toluonitriles, as compared with phenylacetonitrile; and (3) by the total replacement of the hydrogen atoms in the nucleus as in hexachlorobenzene and hexamethylbenzene, or by the addition of six atoms of chlorine as in hexachlorocyclohexane.

The substances examined were $p$-dichloro- and $p$-dibromo-benzenes, $o-, m$-, and $p$-chlorobromobenzenes, benzonitrile, $o-, m-$, and $p$-toluonitriles, hexachlorobenzene, hexamethylbenzene, hexachlorocyclohexane, phenylacetonitrile, benzyl chloride, and benzyl alcohol.

It may be recalled that Baly (T., 1911, 99, 856) re-investigated the absorption spectra of solutions of chlorobenzene, the dichlorobenzenes, and the chlorotoluenes. 
The experimental methods have been described before.

p-Dichlorobenzene.-Baly (loc. cit.) has shown that the substance has five solution bands; the most refrangible of which is very weak, and that $o$ - and $m$-dichlorobenzenes have only four.

The vapour of the substance was examined in a $200 \mathrm{~mm}$. tube at temperatures and pressures varying from $40^{\circ}$ and $767 \mathrm{~mm}$. to $70^{\circ}$ and $827 \mathrm{~mm}$. At the former temperature there appeared eighty-one bands, which have been measured and classified. These bands can be separated into a series of groups of varying intensities, the most refrangible constituent of each of which is the strongest. The following numbers give the position of the heads of the more outstanding groups:

\begin{tabular}{|c|c|c|c|c|c|}
\hline$\lambda$ & Intensity. & $\begin{array}{l}\text { No. } \\
\text { of } \\
\text { bands }\end{array}$ & $\lambda$ & Intensity. & $\begin{array}{l}\text { No. } \\
\text { of } \\
\text { bands }\end{array}$ \\
\hline 84 & Moderately strong.... & 8 & 2692 & Fairly strong ... & 6 \\
\hline & 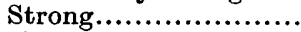 & 16 & 2665 & Fairl & 7 \\
\hline 276 & Moderately strong..... & 12 & 2640 & Fairly strong ........ & 5 \\
\hline & strong...... & 8 & & Moderately weak ..... & 3 \\
\hline 871 & Strong. & 10 & 2546 & Moderately weak ..... & 6 \\
\hline
\end{tabular}

It is of some importance to note that several of these groups can be correlated with four of the solution bands described by Baly, for example:

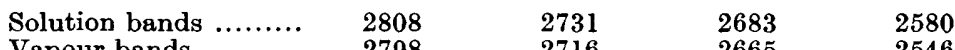

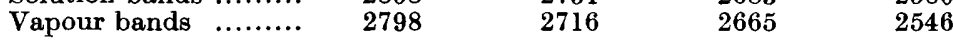

Solution not only causes a closing up of the separate constituents, but also shifts the bands more towards the red.

p-Dibromobenzene.-The alcoholic solution (Fig. 1) showed three well-marked bands and a doubtful one at about $1 / \lambda 3859$ ( $\lambda$ 2590). There does not appear to be a well-marked band beyond this, but the somewhat rapid absorption to about $1 / \lambda 4000$ ( $\lambda 2498$ ) may indicate a widening out of a very diffuse band. The bands are much weaker than the corresponding bands of $p$-dichlorobenzene, and they are shifted a little more towards the red. The rapid step-out of the line of general absorption between $1 / \lambda 4200$ ( $\lambda$ 2380) and $1 / \lambda 4660$ ( $\lambda 2142$ ) may indicate a large band which extends into the Schumann region, for a similar phenomenon was observed in $p$-dichlorobenzene in a $N / 10,000$-solution, although it was not so well marked.

The vapour of the substance was examined in a $200 \mathrm{~mm}$. tube at temperatures and pressures varying between $70^{\circ}$ and $827 \mathrm{~mm}$. and $120^{\circ}$ and $927 \mathrm{~mm}$. The number of bands observed was thirtyone, and these have all been measured and classified. Like the bands in the vapour of $p$-dichlorobenzene, they can be arranged in a series of groups of varying degrees of intensity. The following 
numbers give the position of the bands of the stronger groups, together with the positions of the corresponding three stronger solution bands :

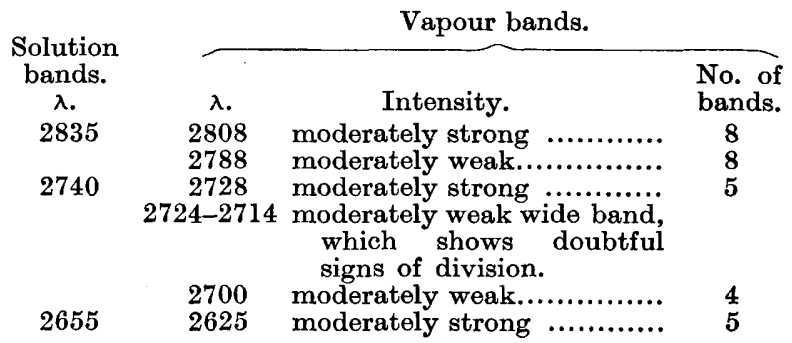

A comparison of the vapour bands of $p$-dichloro and $p$-dibromobenzenes showed that, generally speaking, they appeared to be more diffuse and wider in $p$-dibromobenzene and were fewer in number.

Some of the bands in both substances occurred in groups of three, the most refrangible constituent of each of which was the strongest. These triplets are more frequent in $p$-dichlorobenzene. The following groups of triplets in the two compounds are fairly comparable in appearance: the numbers give the wave-lengths of the most refrangible constituent:

$\begin{array}{lllll}p \text {-dichlorobenzene } & \ldots & 2798 & 2790 & 2783 \\ p \text {-dibromobenzene...... } & 2808 & \mathbf{2 7 9 5} & \mathbf{2 7 8 8}\end{array}$

These three groups of triplets are not unlike the groups found in $p$-dichlorobenzene at $2835,2827,2818,2811$.

The differences in the solution and the vapour phenomena are exactly like the differences observed with substances previously examined, in that all the vapour bands disappear in solution and are replaced by a few wide diffuse bands. The marked difference between the absorption phenomena of the isomeric substances is also noteworthy. As the temperature and the pressure increase, the vapour bands widen into each other in such a manner that the phenomena become comparable with those observed in solution, the chief difference being one of position.

$\mathrm{o}$-, $\mathrm{m}$-, and $\mathrm{p}$-Chlorobromobenzenes.-The alcoholic solutions (Fig. 1) showed three well-marked bands. The bands of the orthoand meta-compounds are more comparable in appearance with one another than with those of the para-compounds. The bands of the meta-compound are a trifle stronger than those of the ortho-compound, and are shifted a little more towards the red end. The bands of the para-compound are shifted still more towards the red, and are slightly wider and more diffuse; the most refrangible band is very weak and diffuse as compared with the corresponding 
band of the ortho and meta-compounds. The rapid widening of the most refrangible band of all the three compounds is also noteworthy, for it may indicate traces of other bands.

The vapour of o-chlorobromobenzene was examined at temperatures and pressures ranging between $50^{\circ}$ and $762 \mathrm{~mm}$. and $90^{\circ}$

Fig, 1.

Oscillation frequencies.

$\begin{array}{lllllllllllllllll}34 & 36 & 38 & 40 & 42 & 44 & 46 & & 34 & 36 & 38 & 40 & 42 & 44 & 46 & 48\end{array}$

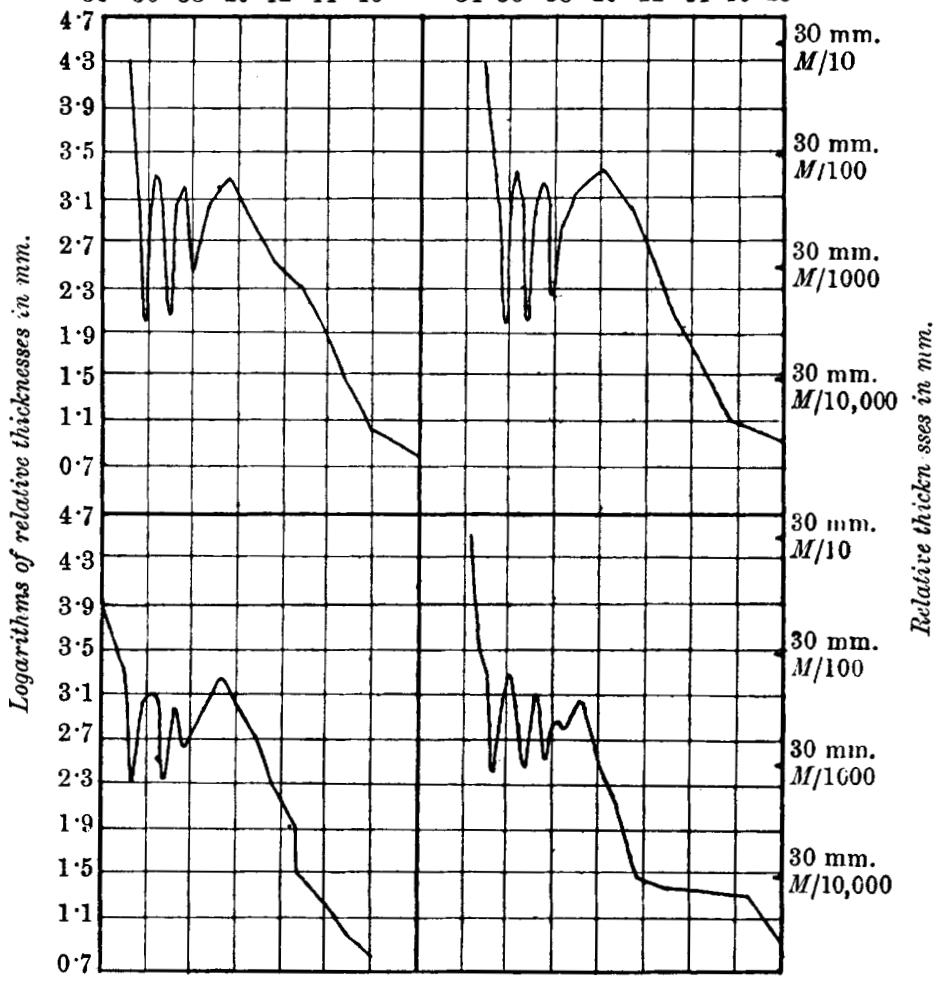

o-Chlorobromobenzene.

Upper curves :

$\mathrm{p}$-Chlorobromobenzene.

Lower curves :

and $842 \mathrm{~mm}$. The total number of bands observed was sixty, and they could be separated and classified into various groups or series of groups. The following numbers give the position of the strongest and most refrangible constituent or head of three outstanding groups and the position of the heads of the corresponding single solution bands: 


\begin{tabular}{|c|c|c|c|c|}
\hline & & & Vapour bands. & \\
\hline & $\begin{array}{c}\text { Solution } \\
\text { bands. } \\
\lambda .\end{array}$ & $\lambda$. & Intensity. & $\begin{array}{l}\text { No. of } \\
\text { bands. }\end{array}$ \\
\hline & 2785 & 2765 & very strong........... & 16 \\
\hline $0 . \mathrm{C}_{6} \mathrm{H}_{4} \mathrm{ClBr}$ & 2700 & 2685 & very strong............. & 19 \\
\hline & 2630 & 2623 & moderately strong............... & 14 \\
\hline & 2790 & 2770 & strong ............................. & 15 \\
\hline$m \cdot \mathrm{C}_{6} \mathrm{H}_{4} \mathrm{ClBr}$ & 2710 & 2690 & strong ................................ & 17 \\
\hline & 2640 & 2622 & moderately strong............... & 11 \\
\hline & 2825 & 2800 & strong .............................. & 17 \\
\hline & 2730 & 2720 & moderately strong $\ldots \ldots \ldots \ldots . . .$. & 7 \\
\hline$p-\mathrm{C}_{6} \mathrm{H}_{4} \mathrm{CIBr}$ & 2650 & $2632-2620$ & $\begin{array}{l}0 \text { a diffuse band which shows } \\
\text { doubtful signs of division. }\end{array}$ & \\
\hline
\end{tabular}

The vapour of $m$-chlorobromobenzene was examined between $50^{\circ}$ and $762 \mathrm{~mm}$. and $90^{\circ}$ and $842 \mathrm{~mm}$. The total number of bands observed was fifty-five, and these also could be divided into various groups. The numbers in the table give the position of the bands of the larger groups and the corresponding single solution bands:

The vapour of $p$-chlorobromobenzene was examined at similar temperatures and pressures, and ninety-eight bands were measured and classified. In the preceding table three of the groups of bands are compared with three corresponding solution bands.

The vapour bands of $o$ - and $m$-chlorobromobenzene have a closer similarity to one another than to those of the para-compound. For example, each of a group of bands the heads of which in the ortho-compound are at $2765,2685,2623$, has a similar appearance to the groups at $2770,2690,2622$ in the meta-compound.

In the para-compound there are groups of bands which are different from any noticed in the ortho- and meta-compounds. In these instances the constituents of each group are much closer together, and tend to produce a series of wide diffuse bands; one outstanding group of the para-compound at 2800 is quite comparable with the groups 2765 and 2770 of the ortho- and metacompounds. It is also noteworthy that the three outstanding groups of the ortho-compound at 2765, 2685,2623, and of the meta-compound at $2770,2690,2622$ are not unlike the groups of bands the heads of which in chlorobenzene are at 2698 and 2661, and in bromobenzene at 2707 and 2666 (loc. cit.).

The chief groups of the meta-compound are also not unlike those of $m$-dichlorobenzene (loc. cit.) except that the bands of the latter are shifted more towards the red end. Similarly, group 2765 of the ortho-compound compares well in appearance with group 2760 of o-dichlorobenzene, and, to a more doubtful extent, group 2685 of the former compound compares with group 2682 of the latter (loc. cit.), but there is a greater shift towards the red end in the case of o-chlorobromobenzene. Similar comparisons extend to the groups in $o$-dibromobenzene, but the bands of the latter are 
shifted more towards the red. Also, the chief groups in $m$-chlorobromobenzene are not unlike those of $m$-dichlorobenzene, except that the former are shifted more toward the red, and are also like those of $m$-dibromobenzene, but the latter again are shifted more towards the red end.

The following groups of bands in $p$-chlorobromobenzene and $p$-dichlorobenzene are fairly comparable. The numbers are the wave-lengths of the more refrangible constituent of each group:

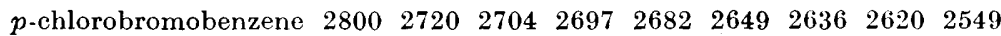

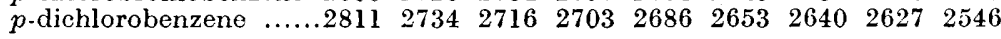

The following groups of bands in $p$-chlorobromobenzene and $p$-dibromobenzene are also comparable in general appearance:

$\begin{array}{llllll}p \text {-chlorobromobenzene } & \ldots \ldots \ldots & 2800 & 2720 & 2704 & 2691\end{array}$

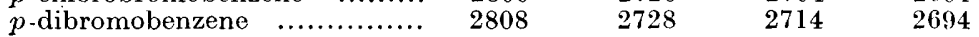

The differences in the solution and the vapour phenomena are again exactly like the differences observed in other substances (loc. cit.), namely, that, as the temperature and the pressure are increased, the bands widen into each other; gradually the numerous vapour bands disappear, and are replaced by a few diffuse wide bands. It is important to notice, too, that, as in the dibromobenzenes, there is a considerable number of vapour bands in the chlorobromobenzenes. There has been no elimination of these bands like that observed in the iodobenzenes previously investigated (loc. cit.).

Benzonitrile.-The solution curve (Fig. 3) shows three bands; the rapid widening of the most refrangible band on the more refrangible side may indicate the presence of other very weak bands. The rapid step-out of the line between $1 / \lambda 4400$ and $1 / \lambda 4700$ ( $\lambda 2270$ and $\lambda 2130)$ may also indicate the presence of a large band which extends into the Schumann region. It has been shown by Baly (loc. cit.), and the author has confirmed this observation, that chlorobenzene has seven solution bands, the most refrangible of which is extremely weak. The position of the benzonitrile bands is shifted much more towards the red end, and they are also stronger than the bands of chlorobenzene. The introduction of the nitrile group, therefore, has modified the absorption very considerably.

The vapour of benzonitrile was examined at temperatures and pressures varying between $50^{\circ}$ and $852 \mathrm{~mm}$. and $100^{\circ}$ and $952 \mathrm{~mm}$. There were fifty-three bands observed, and these have been measured and classified into various groups and series. The following numbers give the heads of three of the more outstanding groups, together with the head of the corresponding solution band. 


\begin{tabular}{|c|c|c|c|c|}
\hline & & & Vapour band. & \\
\hline & $\begin{array}{l}\text { Solution } \\
\text { band. } \\
\lambda .\end{array}$ & $\lambda$. & Intensity. & $\begin{array}{l}\text { No. of } \\
\text { bands. }\end{array}$ \\
\hline & 2785 & 2738 & strong ............... & 13 \\
\hline $\mathrm{C}_{6} \mathrm{H}_{5} \cdot \mathrm{CN}$ & $\begin{array}{l}2710 \\
2640\end{array}$ & $\begin{array}{l}2687 \\
2614 \text { to } 2604\end{array}$ & 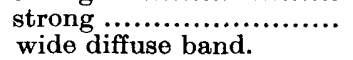 & 11 \\
\hline & 2850 & 2796 & 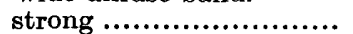 & 8 \\
\hline$o \cdot \mathrm{C}_{6} \mathrm{H}_{4} \mathrm{Me}^{\circ} \mathrm{CN}$ & $\begin{array}{l}2780 \\
2700\end{array}$ & $\begin{array}{c}2719 \\
2692 \text { to } 2628\end{array}$ & $\begin{array}{l}\text { moderately strong.......... } \\
\text { a series of weak bands. }\end{array}$ & 11 \\
\hline$m-\mathrm{C}_{6} \mathrm{H}_{4} \mathrm{Me}^{\cdot} \mathrm{CN}$ & $\begin{array}{l}2840 \\
2776 \\
2740\end{array}$ & $\begin{array}{l}2794 \\
2718 \\
2710 \text { to } 2696\end{array}$ & 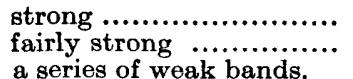 & $\begin{array}{r}7 \\
11\end{array}$ \\
\hline & 2790 & 2761 & fairly strong . ................ & 7 \\
\hline$p \cdot \mathrm{C}_{6} \mathrm{H}_{4} \mathrm{Me} \cdot \mathrm{CN}$ & 2730 & 2702 & 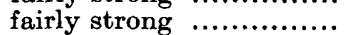 & 16 \\
\hline & 2710 & 2666 & fairly strong.............. & 11 \\
\hline
\end{tabular}

The series of bands the head of which is at $\lambda 2738$ in benzonitrile compare fairly well in appearance with a group of bands of chlorobenzene described previously (loc. cit.), the head of which is at $\lambda 2698$, and the series, the head of which is at $\lambda 2687$, is comparable with the group of chlorobenzene at $\lambda 2661$.

The position of the bands as compared with those of aniline (Purvis, T., 1910, 97, 1546) also shows that there has been a considerable shift of the solution bands and of the vapour bands towards the red.

The general results are similar to those of other substances in that all the vapour bands are replaced by a few solution bands, and, as the temperature and the pressure increase, widen into each other, and the phenomena gradually become comparable with the solution phenomena.

o-, m-, and p-Toluonitriles.-The solution curves (Fig. 2) show that in the ortho-compound there are three bands the most refrangible of which widen out on the more refrangible side; that in the meta-compound there are also three bands, whereas in the para-compound there are indications of a weak fourth band. Besides these somewhat narrow diffuse bands there are indications of a large band in the ortho- and meta-compounds on the more refrangible side and extending into the Schumann region. This band, in the para-compound, is fairly well marked, as shown by the curve. The least refrangible band of the first three of the paracompound is much sharper than the corresponding band in the ortho- and meta-compounds; the latter are very diffuse. It is also noteworthy that the toluonitrile bands are much weaker than the benzonitrile bands (Fig. 3), but the least refrangible band of $p$-toluonitrile compares well with that of benzonitrile in intensity.

The vapours of the three substances were examined in a $200 \mathrm{~mm}$. tube at temperatures and pressures ranging from $16^{\circ}$ and $755 \mathrm{~mm}$. to $100^{\circ}$ and $922 \mathrm{~mm}$. In the case of the ortho-compound the 
HALOGEN AND NITRILE DERIVATIVES, ETC.

number of bands observed was thirty-three, which have been measured and classified. The numbers in the table give the position of the more outstanding groups compared with the corresponding solution bands.

The vapour of $m$-toluonitrile was examined from $17^{\circ}$ and $755 \mathrm{~mm}$. to $100^{\circ}$ and $910 \mathrm{~mm}$., and thirty-seven bands were observed and

Fia. 2.

Oscillation frequencies.

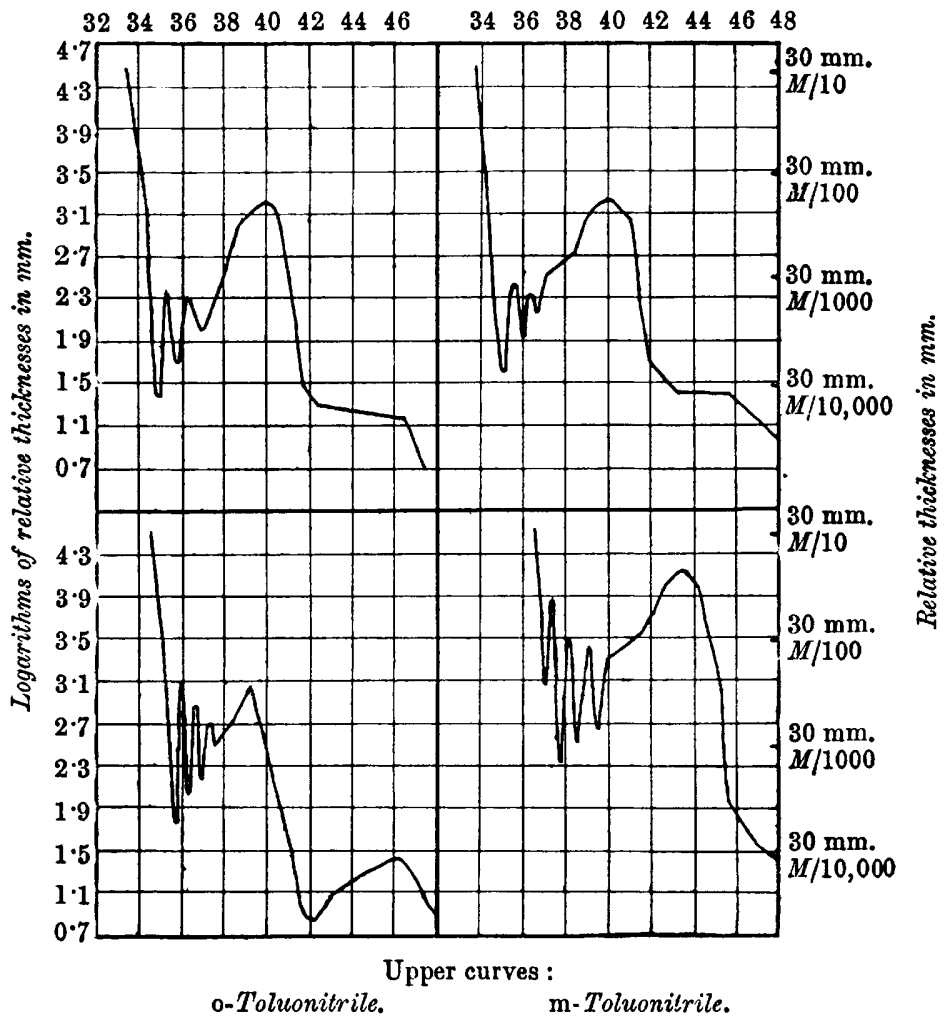

Lower curves :

$\mathrm{p}$-Toluonitrile.

Phenylacetonitrile.

measured. The numbers in the table compare the corresponding groups of the solution bands.

The vapour of $p$-toluonitrile was examined between $15^{\circ}$ and $749 \mathrm{~mm}$. and $110^{\circ}$ and $1010 \mathrm{~mm}$., and thirty-seven bands were observed and measured. The numbers in the preceding table compare the chief groups with the solution bands. 
The large solution band in the extreme ultra-violet region appears also in the vapours of the three compounds, and it is especially well marked in the vapour of the para-compound. It does not break up into a series of finer bands, although there is a weaker diffuse band on its less refrangible side.

There is a closer resemblance between various groups of the vapour bands in the ortho and meta-compounds than appears in the para-compound; but the following groups of bands in all three compounds, and a group of bands in benzonitrile, are fairly comparable. The numbers represent the heads of the constituent band on the more refrangible side:

$\begin{array}{llcc}o \text {-toluonitrile } \ldots \ldots \ldots \ldots \ldots \ldots & 2796 & 2719 & 2703 \\ m \text {-toluonitrile............... } & 2794 & 2718 & 2696 \\ p \text {-toluonitrile } \ldots \ldots \ldots \ldots \ldots \ldots & 2761 & 2721 & 2713 \\ \text { benzonitrile } \ldots \ldots \ldots \ldots \ldots \ldots & 2738 & - & -\end{array}$

Again, the group of bands at 2796 in o-toluonitrile is comparable with the group at 2714 in o-chlorobenzene, and with the group at 2732 in $m$-chlorobenzene described previously (loc. cit.). At the same time it should be clearly understood that no exact comparison of all these various vapour bands was attempted. Such a definite comparison would mean that the radiant energy should have passed through the same number of molecules, and that the dispersion should be greater than was employed. Neither of these conditions is implied in the description of the observed phenomena.

The differences in the solution and the vapour phenomena of benzonitrile and of the three toluonitriles are again like those observed in other substances described previously (loc. cit.) in that all the numerous vapour bands disappear in solution and are replaced by a few wide, diffuse bands; that the isomeric substances show differences amongst themselves; and that the vapour bands gradually widen into each other as the temperature and the pressure increase, and the phenomena then become not unlike the solution phenomena.

Phenylacetonitrile.-The solution curve (Fig. 2) shows four wellmarked bands, and the rapid step-out of the rays between $1 / \lambda 4000$ and $1 / \lambda 4150(\lambda 2498-\lambda 2408)$ probably indicates one or more very weak, diffuse bands which widen into each other. It is important to notice that the bands are weaker than the three bands of benzonitrile, and that the latter are shifted more towards the red end. The introduction of the cyanogen group in the aliphatic side-chain has enabled the benzene nucleus to regain, in some measure, the characteristic benzene solution bands.

The comparatively high boiling point of phenylacetonitrile made it difficult to examine the vapour of the substance, but in a 
$200 \mathrm{~mm}$. tube at various temperatures and at $767 \mathrm{~mm}$. pressure the following phenomena were observed:

$90^{\circ}$ Very doubtful absorption between $\lambda 2640$ and $\lambda 2620$, between 2565 and $\lambda 2550$, and between $\lambda 2520$ and $\lambda 2500$; the rays were then transmitted to $\lambda 2200$.

$120^{\circ}$ Rays were feebly absorbed between $\lambda 2640$ and $\lambda 2620$, between $\lambda 2565$ and $\lambda 2550$, and between $\lambda 2520$ and $\lambda 2500$; then transmitted to about $\lambda 2270$.

$130^{\circ}$ The rays were absorbed between $\lambda 2660$ and $\lambda 2620$, between $\lambda 2565$ and $\lambda 2550$; then feebly transmitted to $\lambda 2510$.

$150^{\circ}$ The rays were absorbed from about $\lambda 2670$, but Cd. 2573 was just visible.

It appears, therefore, that the cyanogen group has destroyed the twenty-two narrow vapour bands of toluene described by

FIG. 3.

Oscillation frequencies.

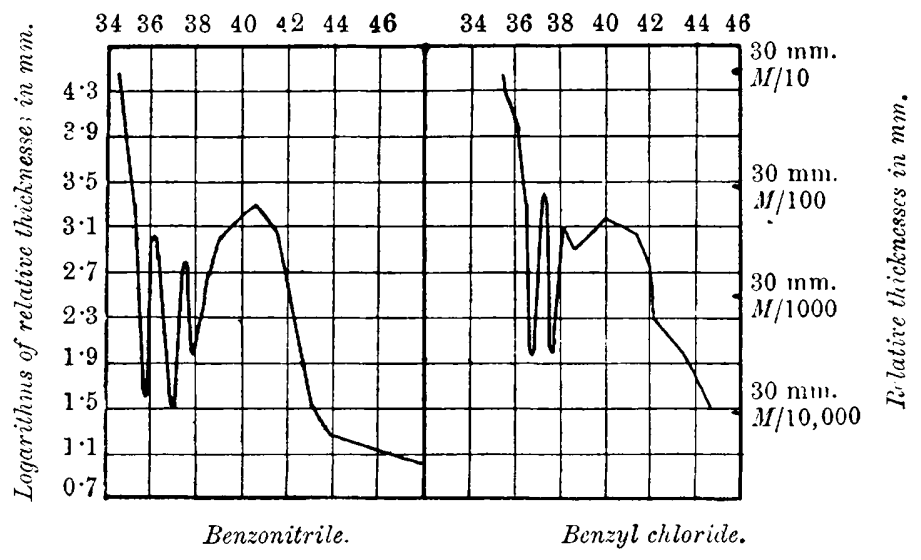

Hartley (Phil. Trans., 1907, [A], 208, 475), and that the solution and the vapour phenomena are fairly comparable.

Benzyl Chloride.--The solution curve (Fig. 3) shows two moderately strong bands and a very weak one on the more refrangible side. Baly and Collie (T., 1905, 87, 1332) describe three solution bands of the substance. These bands are much weaker than the phenylacetonitrile bands, and also much weaker than the toluene bands.

The easy decomposition of this substance made the observations of the absorption spectra of the vapour very difficult, but the following phenomena were observed when the vapour was at various temperatures and pressures: 
$60^{\circ}$ and $806 \mathrm{~mm}$. The rays were feebly absorbed between $\lambda 2700$ and $\lambda 2695$; between $\lambda 2660$ and $\lambda 2640$, between $\lambda 2600$ and $\lambda 2590$, and then transmitted to $\lambda 2310$.

$75^{\circ}$ and $836 \mathrm{~mm}$. Rays were fairly well absorbed between $\lambda 2710$ and $\lambda 2695$ (Cd. line 2573 well marked), and then absorbed to about $\lambda 2520$. From here, to about $\lambda 2420$, the rays were very feebly transmitted.

$90^{\circ}$ and $866 \mathrm{~mm}$. The rays were absorbed from $\lambda 2720$.

As in phenylacetonitrile, there were no vapour bands like those found in toluene or in the chlorotoluenes (loc. cit.).

These two substances were also compared with benzyl alcohol, and the vapour of the latter substance showed the following phenomena :

$\begin{array}{lcc}t^{\circ} & \begin{array}{c}\text { Pressure } \\ \text { in mm. }\end{array} \\ 75 & 836 & \begin{array}{c}\text { The rays showed doubtful signs of weakening between } \\ \lambda 2650 \text { and } \lambda 2625 ; \text { and were then transmitted to } \lambda 2420 .\end{array} \\ 90 & 866 & \begin{array}{c}\text { The rays showed very feeble absorption between } \lambda 2650 \\ \text { and } \lambda 2620 \text {, between } \lambda 2560 \text { and } \lambda 2550 \text {, and were then } \\ \text { feebly transmitted to } \lambda 2470 .\end{array}\end{array}$

In benzyl alcohol, therefore, all the vapour bands of toluene were absent. Benzyl alcohol is easily oxidised to the aldehyde, but the fact that no aldehyde bands were observed in the vapour showed that there had been no oxidation under the experimental conditions. The tube was always filled with nitrogen gas before the commencement of the experiments.

Hexachlorocyclohexane.-Hartley (T., 1881, 39, 153) showed that alcoholic solutions did not exhibit bands, and were remarkably transparent. The author has repeated these experiments, and confirmed the observations. The following numbers give the position to which the rays are transmitted through various thicknesses of a $M / 100$-solution in alcohol: $80 \mathrm{~mm}$. to 2550 (but $\mathrm{Cd} 2313$ was just visible); $70 \mathrm{~mm}$. to 2480 (but $\mathrm{Cd} 2329,2321,2313$ were just visible); $60 \mathrm{~mm}$. to 2450 (but Cd 2329, 2321, 2313, and 2265 fairly well-marked); $50 \mathrm{~mm}$. to $2270 ; 40 \mathrm{~mm}$. to $2200 ; 30 \mathrm{~mm}$. to 2200 ; $20 \mathrm{~mm}$. to $2150 ; 10 \mathrm{~mm}$. to 2144 .

The comparatively feeble vapour pressure made the examination of the vapour of the substance difficult, but the following numbers give the positions to which the rays were transmitted in the $200 \mathrm{~mm}$. tube at $747 \mathrm{~mm}$. pressure and at various temperatures: At $150^{\circ}$ the rays were transmitted to $\lambda 2144 ; 160^{\circ}$ to $2200 ; 170^{\circ}$ to $2290 ; 180^{\circ}$ to $2340 ; 190^{\circ}$ to $2415 ; 200^{\circ}$ to 2420 . Like the solution, the vapour, so far as it was examined, showed no bands.

Hexachlorobenzene. - This substance is not very soluble, but an approximately $M / 1000$ alcoholic solution was obtained. No bands were observed, and the following numbers give the positions to 
which the rays were transmitted through various strengths and thicknesses:

$M / 1000,90 \mathrm{~mm}$. the rays were transmitted to $\lambda 2770 ; 70 \mathrm{~mm}$. to $2760 ; 60 \mathrm{~mm}$. to $2750 ; 40 \mathrm{~mm}$. to $2730 ; 30 \mathrm{~mm}$. to 2690 ; $20 \mathrm{~mm}$. to $2660 ; 10 \mathrm{~mm}$. to $2590 ; 6 \mathrm{~mm}$. to 2530 .

$M / 10,000,30 \mathrm{~mm}$. the rays were transmitted to $\lambda 2460$; $20 \mathrm{~mm}$. to $2450 ; 16 \mathrm{~mm}$. to $2420 ; 14 \mathrm{~mm}$. to $2280 ; 6 \mathrm{~mm}$. to 2240 .

The comparatively weak vapour pressure of the substance made the investigation of its vapour difficult, but the following numbers give the position to which the rays were transmitted in the $200 \mathrm{~mm}$. tube and at $747 \mathrm{~mm}$.: At $180^{\circ}$ the rays were transmitted to $\lambda 2350 ; 190^{\circ}$ to $2430 ; 200^{\circ}$ to $2520 ; 210^{\circ}$ to $2570 ; 220^{\circ}$ to 2630 .

There were no bands of selective absorption in the vapour so far as it was examined, nor is it likely there would be at higher temperatures.

Hexamethylbenzene.-Solutions of the substance were examined, but no bands were seen. The following numbers give the positions to which the rays were transmitted through various strengths and thicknesses :

$M / 100,60 \mathrm{~mm}$. the rays were transmitted to $\lambda 2450 ; 50 \mathrm{~mm}$. to $2400 ; 40 \mathrm{~mm}$. to $2390 ; 30 \mathrm{~mm}$. to $2380 ; 20 \mathrm{~mm}$. to $2360 ; 10 \mathrm{~mm}$. to 2340 .

$M / 1000,30 \mathrm{~mm}$. the rays were transmitted to $\lambda 2310 ; 20 \mathrm{~mm}$. to $2250 ; 10 \mathrm{~mm}$. to 2200 .

The vapour of the substance was not examined.

The well-known seven solution bands and the more numerous vapour bands of benzene have completely disappeared from the solutions and vapours of the last three substances. It is also evident that hexachlorocyclohexane is much more transparent than hexachlorobenzene and hexamethylbenzene, and that hexamethylbenzene is more transparent than hexachlorobenzene.

\section{General Results.}

The chief results of the preceding observations are: (1) The considerable number of vapour bands in $p$-dichloro- and $p$-dibromobenzenes, in $o-, m$-, and $p$-chlorobromobenzenes, in benzonitrile, and in $o-, m-$, and $p$-toluonitriles, which disappear when the substances are in solution and are replaced by a few moderately wide, diffuse bands. (2) The marked differences in the absorption phenomena of the isomeric substances, especially in the para-compounds as compared with the ortho- and meta-compounds; these differences are more strongly marked in the vapours than in the solutions. (3) The absence of narrow vapour bands in phenylacetoVOL. CVII.

L L 
nitrile, benzyl chloride, and benzyl alcohol. (4) The complete elimination of both vapour bands and solution bands in hexachlorocyclohexane, hexachlorobenzene, and hexamethylbenzene. (5) The similarity of the vapour bands and the solution bands at the higher temperatures and pressures in those compounds which exhibit a series of finer vapour bands at the lower temperatures and pressures.

It has already been suggested (loc. cit.) that the fundamental vibrations of the atoms in a molecule are influenced by their type and nature as well as by their orientation and by the physical conditions of the system, and that the final adjustment of the oscillations producing selective absorption is controlled by these conditions as well as by the distribution and reaction of the vibrations produced by the radiant energy. This energy reacts differently on different atoms and atomic groups, and the oscillatory movements which determine the nature and extent of the absorption are modified by the interdependence and relationships of the various oscillatory centres.

It is considered that the absorption depends upon an influence inherent in the atom, which is electronic and, to a large extent, independent of the weight, but is controlled by the orientation and relationship with other atouns or groups, which also act as oscillatory centres. If the specific absorption depended solely on the weight, there should be no vapour bands in the dibromobenzenes, for these substances are heavier than iodobenzene, which shows no bands (loc. cit.). The argument will apply à fortiori to nitrobenzene, which has no fine vapour bands, and only traces of a weak solution band (loc. cit.). That each atom or group reacts on the vibrations of other groups according to its position is indicated by the different phenomena exhibited by the isomeric substances, and is further strengthened by the fact that phenylacetonitrile has more solution bands than the toluonitriles, and that the vapour bands of toluene are completely destroyed in phenylacetonitrile, whereas there is a considerable number of vapour bands in each of the toluonitriles.

It may be recalled that there are no fine vapour bands in substances containing two similar nuclei, such as diphenyl (Purvis, T., 1914, 105, 590); all the numerous benzene vapour bands are wholly eliminated. Herein there is a strict comparison with the phenomena shown by hexachlorobenzene and hexachlorocyclohexane; and, if valency is considered to have an electronic origin, the remarkable transparency of hexachlorocyclohexane may be explained by assuming that the oscillations are damped by the chlorine atoms, whereas in hexachlorobenzene, which is not so 
THE ACTION OF ALDEHYDES ON THE GRIGNARD REAGENT. 509

transparent, the valencies are still unsaturated to some extent. On the other hand, where it may be considered that the nuclei are not so closely connected as in diphenylmethane, the solution bands show (loc. cit.) that the oscillations have a freer movement, but not sufficiently free to produce the fine vapour bands. At the same time, the absence of the finer vapour bands in phenylacetonitrile, benzyl chloride, and benzyl alcohol is not explained by such a suggestion. It may be that the lengthening of the sidechain in these compounds by the added atoms or groups neutralises the fundamental oscillations of the nucleus by enabling them to react on the nucleus to such an extent that only a few diffuse bands are produced.

In the solutions, the external influence of the solvent modifies the oscillations, so that the number of individual bands is greatly decreased; it is noteworthy that the comparatively broad, diffuse solution bands can often be compared with various groups of the vapour bands. A group of vapour bands would seem to close up under the influence of the solvent to form a diffuse wide band, whereas in other instances the vapour bands are so weak that they practically disappear when the substance is in solution.

I desire to thank the Government Grant Committee of the Royal Society, by whose assistance the greater part of the cost of the research has been defrayed.

University Chamical Laboratory, CAMBRIDGE.

[Received, Jan. 28th, 1915.] 